\title{
Desafios para o Serviço Social em tempo de avanços do conservadorismo
}

Challenges for social work in advance time of conservative

Maria Carmelita Yazbek ${ }^{a}$

(D) https://orcid.org/0000-0002-4785-472X

Raquel Raichelis Degenszajn ${ }^{a}$

(D) https://orcid.org/0000-0003-3275-3755

Rosangela Dias Oliveira da Paz

(D) https://orcid.org/0000-0003-3547-1286

ste número da Revista Serviço Social \& Sociedade chega ao público no momento em que o candidato da extrema direita saiu vencedor nas eleições presidenciais de 2018, que evidenciaram um processo de radicalização da política brasileira sem precedentes desde o início da Nova República, no contexto de uma profunda crise política, econômica e social, marcada pelo alto desemprego, precarização e informalização das relações de trabalho, empobrecimento da população e redução drástica dos recursos destinados às políticas sociais. A emergência da(s) direita(s) num cenário nacional e internacional de crescimento do conservadorismo de traços fascistas expõe a face hiperautoritária do neoliberalismo (Dardot; Laval, 2016) na atual quadra do capitalismo contemporâneo.

Contudo, cabe aos movimentos sociais, aos partidos políticos, às organizações sindicais, às universidades, ao associativismo civil, a tarefa de mobilizar energias criativas e a razão crítica para aprofundar o debate sobre 
os rumos da nossa ameaçada democracia, não apenas para decifrar o tempo presente, mas para resistir e transformá-lo.

É nessa direção que a Revista Serviço Social \& Sociedade reafirma seu compromisso de contribuir para fazer avançar o debate crítico na defesa das conquistas democráticas e constitucionais e dos valores que fundamentam o projeto ético-político do Serviço Social brasileiro.

Mas pensar o tempo presente implica trazer ao debate as marcas históricas da formação sócio-histórica brasileira, com suas persistentes desigualdades sociais criadas pela divisão internacional do trabalho onde se inserem os países da periferia capitalista dependente. Tais processos redimensionam a constitutiva superexploração da força de trabalho e a tradição autoritária e excludente do Estado e da sociedade brasileira.

O avanço do pensamento conservador e reacionário na atualidade questiona valores básicos do Estado democrático de direito, buscando construir uma nova política funcional à sociabilidade do capital, moldando um perfil particular para a questão social latino-americana e global e a desigualdade fundante que a constitui.

Como sabemos, a desigualdade e a concentração de renda que se intensificam no padrão atual de acumulação capitalista resultam de mudanças na esfera da produção, associadas à nova hegemonia liberal-financeira, e trazem como consequência a radicalização da questão social como questão política e pública derivada do acirramento da luta de classes, com consequências nefastas para a "classe que vive do trabalho", pela manutenção de taxas elevadas de desemprego, insegurança e instabilidade nos empregos, crescimento do trabalho informal, terceirizações e contratos flexíveis por prazos determinados, entre outros aspectos.

Como observou Antunes (2018, p. 120), a combinação entre neoliberalismo, financeirização da economia e reestruturação produtiva acarretou profundas transformações na composição da classe trabalhadora e em sua morfologia.

A reestruturação produtiva do capital e as estratégias neoliberais para o enfrentamento das crises que se aprofundam há pelo menos quatro décadas no mundo e no Brasil vêm provocando a corrosão persistente e ampliada 
do trabalho contratado e regulamentado de matriz tayloriano-fordista, dominante no século $\mathrm{XX}$, sendo substituída pelas mais diversas formas de flexibilização do trabalho, inspiradas pelo toyotismo ou modelo japonês, com vistas a ampliar os mecanismos de extração do sobretrabalho em tempo cada vez menor e com menor custo (Antunes; Druck, 2014).

Como consequência, aprofunda-se a tendência do capital de redução do número de trabalhadores contratados, gerando economia do trabalho vivo, potencializada pela incorporação em larga escala de tecnologias microeletrônicas poupadoras de força de trabalho. Amplia-se o desemprego estrutural além da precarização e deterioração da qualidade do trabalho, dos salários e das condições em que ele é exercido, que se agravam ainda mais considerando recortes de gênero, geração, raça e etnia, com profundas mudanças nas formas de ser da classe trabalhadora, com impactos na materialidade e na subjetividade individual e coletiva (Raichelis, 2018, p. 51-52).

O trabalho de assistentes sociais, como parte integrante das relações sociais de trabalho na sociedade burguesa e do conjunto da classe trabalhadora e de suas lutas, não se autonomiza da dinâmica geral do mercado de trabalho. É possível observar que assistentes sociais experimentam, assim como os demais trabalhadores assalariados, a precarização do trabalho não protegido, a insegurança laboral, a baixa e incerta remuneração, a desproteção social e trabalhista, o assédio moral, o sofrimento e o adoecimento decorrentes do trabalho, ou seja, a precarização do trabalho e da vida (Idem, 2018, p. 52).

Pela mediação das políticas sociais, operando dentro de seus limites e de suas possibilidades, a profissão está envolvida diretamente com a construção cotidiana das expressões da sociabilidade capitalista. Desse modo, o atual cenário desafia assistentes sociais brasileiros e latino-americanos, bem como as entidades profissionais associadas em sua tarefa de construção coletiva de ações e enfrentamentos que incidem sobre a formação profissional e o trabalho docente do/a Assistente Social e, ao mesmo tempo, fundamentam as ações de resistências coletivas, nas quais assume papel central a ação política das entidades organizativas do Serviço Social. 
Ao mesmo tempo, precarização e intensificação do trabalho se reproduzem nos espaços profissionais, e no caso do trabalho docente, como aponta um dos artigos, agrega-se o produtivismo acadêmico, especialmente a partir da expansão do ensino superior nos anos 2000, em que pese a importância da criação de novas universidades federais e ampliação do acesso ao ensino superior.

A incorporação da razão instrumental e gerencialista nas políticas e programas sociais, incluindo a política educacional, degrada as condições de trabalho, precarizando os serviços sociais públicos ofertados à população. O empresariamento do ensino superior e a mercantilização do trabalho docente rebaixam a qualidade da formação acadêmica e profissional em todos os níveis, no ensino presencial e na EAD, na graduação e na pós-graduação, questões relevantes no debate sobre os desafios da formação profissional, tratadas por um dos artigos deste número.

Análise mais ampla da formação acadêmica na América Latina comparece no artigo de abertura deste número da Revista Serviço Social \& Sociedade. Trata-se do pronunciamento da professora Marilda V. Iamamoto por ocasião da Conferência Mundial: Serviço Social, Educação e Desenvolvimento Social (SWSD), realizada em Dublin, Irlanda, em julho de 2018, e promovida pela Associação Internacional de Escolas de Serviço Social, que temos a satisfação de veicular para um público mais amplo.

Cabe destacar que nessa Conferência a profa. Marilda recebeu o Prêmio Katherine Kendall, por indicação da Associación Latinoamericana de Enseñanza y Investigación en Trabajo Social (ALAIETS), como forma de reconhecimento por sua trajetória acadêmica e contribuição intelectual ao Serviço Social no Brasil, na América Latina e também na Europa.

Este texto é uma emblemática exposição da força política e organizativa do Serviço Social brasileiro e de seu avanço "na construção de uma proposta essencialmente crítica da formação acadêmico-profissional - nos níveis de graduação, da especialização e da pós-graduação stricto sensu: mestrado e doutorado. Uma educação predominantemente universitária enraizada nas particularidades históricas da América Latina e Caribe, dotada de rigor enquanto disciplina científica, reconhecida como área de conhecimento no campo das Ciências Humanas e Sociais por parte das políticas estatais de 
educação superior; e profissão dotada de legitimidade social junto aos sujeitos sociais com os quais trabalhamos, comprometida com suas necessidades sociais e interesses coletivos".

Nessa direção, o texto realiza uma reconstrução histórico-crítica da formação e do trabalho profissional do Serviço Social na realidade latino-americana, problematizando o contexto de enfrentamento das múltiplas faces da pobreza e das desigualdades que caracterizam o continente, e que continuamente desafiam a profissão. Evidencia ainda como as forças de resistência se colocam nessa conjuntura profundamente adversa para os/ as trabalhadores/as e para os movimentos sociais nesta nuestra América, realidade una e diversa, que se atualiza frente aos permanentes desafios que se apresentam nessas difíceis décadas iniciais do século XXI.

Com esse olhar para os desafios da formação e do trabalho profissional do Serviço Social no Brasil e no contexto latino-americano, o conjunto de artigos que compõem este número aborda, sob ângulos distintos, os sentidos da pobreza, da miséria e das violências no capitalismo globalizado, as novas sociabilidades que requisitam o trabalho especializado de profissionais, o processo histórico e a trajetória da profissão, o debate sobre história, tempo e memória, a determinação ontológica da realidade e o método em Marx, a educação popular e a direção política das entidades da categoria profissional e suas formas de resistência, bem como temáticas que exigem novos olhares, amadurecimento e respostas que reafirmem o compromisso profissional com os direitos humanos e o respeito à diversidade.

\section{Referências}

ANTUNES, Ricardo. O privilégio da servidão - o novo proletariado de serviços na era digital. São Paulo: Boitempo, 2018.

ANTUNES, Ricardo; DRUCK, Graça. A epidemia da terceirização. In: ANTUNES, Ricardo. (org.). Riqueza e miséria do trabalho no Brasil III. São Paulo: Boitempo, 2014.

DARDOT, Pierre; LAVAL, Christian. A nova razão do mundo. São Paulo: Boitempo, 2016. RAICHELIS, Raquel. Serviço Social: trabalho e profissão na trama do capitalismo contemporâneo. In: RAICHELIS, Rachel; VICENTE, Damares; ALBUQUERQUE, Valéria (orgs.). A nova morfologia do trabalho no Serviço Social. São Paulo: Cortez, 2018. 


\section{Sobre as autoras}

Maria CARMelita YazBeK - Doutora em Serviço Social. Bolsista produtividade em pesquisa $1 \mathrm{~A}$ do CNPq. Professora e pesquisadora do Programa de Estudos Pós-Graduados em Serviço Social da PUC-SP.

E-mail: mcyaz@uol.com.br

Raquel Raichelis Degenszajn - Doutora em Serviço Social. Professora do Programa de Estudos Pós-Graduados em Serviço Social da PUC-SP.

E-mail: raichelis@uol.com.br

Rosangela Dias Oliveira da Paz - Doutora em Serviço Social. Professora e pesquisadora do Programa de Estudos Pós-Graduados em Serviço Social da PUC-SP. E-mail:rosapaz@uol.com.br. 